\title{
Guanxi Revisited: An Exploratory Study of Familiar Ties in a Chinese Workplace
}

\author{
Jar-Der Luo \\ Tsinghua University, China
}

ABSTRact Do Chinese people restrict their complex transactions to a trusted inner circle composed of strong ties? Hwang's (1988) study points out that Chinese people often convert unfamiliar ties into familiar ties when the latter become trustworthy people. This conversion is instrumental in ensuring the fulfilment of promises in complex transactions because it contains an element of emotional attachment or moral obligation. This paper employs network data in a Chinese workplace to demonstrate the following points: first, there is indeed a type of guanxi in the Chinese workplace that can be described as 'familiar ties'. Second, familiar ties contain as much trust as friendship ties and more than acquaintance ties. A Chinese person may search for his or her possible partners among strangers, then develop trust within this guanxi and gradually transform the relationship into familiar ties. It is through these ties that interpersonal trust can grow and enable complex transactions.

KEYWORDs familiar tie, friendship, guanxi, instrumental exchange

\section{INTRODUGTION}

Establishing trust is a necessary precondition for completing transactions in hierarchies or in markets (Granovetter, 1985). Williamson's (1996) theory proposed various mechanisms governing complex transactions, in which generalized trust is based on faith in governance mechanisms. Generalized trust is thought of as the key to completing complex transactions, since it provides a person with a sense of confidence to engage in risky exchanges. This type of trust is also taken by Fukuyama (1995) as the foundation on which large modern corporations are built. The Chinese people, however, tend not to trust strangers and tend to conduct complex transactions only with friends and family members (Fukuyama, 1995; Wang \& Liu, 2003). This tendency of the Chinese to distrust outsiders and strangers is frequently cited as the reason why the Chinese have not been able to form modern corporations and engage in large, complex transactions. That is one possible explanation for why a modern capitalist system has not developed in China (Fukuyama, 1995). 
Hwang (1987, 1988) identifies three types of Chinese guanxi (relationships): expressive ties, mixed ties, and instrumental ties. He points out that Chinese often transform trustworthy instrumental ties into mixed ties, which are both expressive and instrumental because they carry an element of emotional attachment or moral obligation to ensure completion of complex transactions. It is within these ties that interpersonal trust can grow. A Chinese person may search for his or her possible partners among strangers, then gradually develop trust through this type of guanxi. Eventually, the guanxi can become a mixed tie with enough trust required to complete a complex deal.

Guanxi is not a unified concept for the Chinese. There are different categories of guanxi, each with its own different behavioural and moral standards. Sociologist Fei (1992) called this phenomenon a 'differential mode of association' [chaxu geju (差序格局)]. Yang (1993) extended Fei's theory and proposed a three-category guanxi model using a concentric circles model. The centre of Chinese guanxi is the familial tie. The major moral requirement of this main category is family-based ethics - i.e., mutual responsibility and reciprocity without a consideration of one's own self-interest. The most peripheral ring is the category of stranger ties, where self-interest is the main concern. The category of familiar ties is positioned in the middle ring between these two kinds of guanxi and is described as the mixture of both family-based ethics and consideration for one's self.

Hwang (1987) further extended Yang's theory by applying different exchange principles to the three guanxi categories. There are expressive ties, instrumental ties, and mixed ties that follow the 'rules of need', 'rules of equity', and 'rules of renqing (favour exchange)', respectively. Yang (2001) demonstrated that Hwang's three exchange principles could also be applied in Yang's (1993) classification. In this article, I will adopt Fei's 'differential mode of association' and Yang's three categories (the concentric circle model) to develop my hypotheses.

Utilizing network data in the Chinese workplace, I will identify familiar ties. Then, I will illustrate that these familiar ties provide more trust than the other two kinds of guanxi. This study parallels Hwang's theory that the existence of familiar ties actually allows Chinese people to engage in complex transactions with anyone, even though the person may at first be a stranger.

\section{A TWO-DIMENSIONAL FRAMEWORK FOR GUANXI}

The number and strength of social ties are key concepts in the study of networks. For instance, information-sharing is often viewed as the function of weak ties (Burt, 1992; Krackhardt \& Hanson, 1993). However, some types of knowledge transfer may not be possible via weak ties. For example, Hansen (2002) found that complex knowledge requires strong ties as the bridge. Tsai (2002) illustrated that strong ties are especially important if there is competition between the two units. In addition, consumers choosing whether to adopt new communication 
technology rely on their network of strong ties, rather than weak ties (Suarez, 2005).

Unlike the dualism stated above, a third type of tie in Chinese guanxi is the familiar tie. Familiar ties form the most important part of a Chinese social network. When a Chinese person uses the general term 'guanxi' they sometimes mean only this category (Chen, Chen, \& Xin, 2004). Chen et al. (2004) indicate that Chinese guanxi has both an instrumental exchange element and emotional involvement element to the relationship, such that Chinese cannot distinguish friendship from rational exchanges aimed at satisfying personal purposes.

The Chinese concept of bao (in Chinese 報; translated as the norm of fair exchange) is the behavioural and moral standard for stranger or acquaintance ties. This standard is operative in instrumental exchanges, such as in social or economic exchange relations. These social exchange relations are at a minimum among acquaintances and may or may not last for a long time. In the interactions with acquaintances, Chinese people are considered individualistic, and therefore the concept of self-interested rational calculation and 'price' bargaining apply (Hwang, 1988; Yang, 1993). The fair exchange principle is a good fit for this category. Hwang describes this principle as 'the rule of equity'. It represents the behavioural standard for acquaintance ties.

The Chinese concept of lun (in Chinese 倫, the moral codes in familial relationships) is the behavioural and moral standard that best suits the category of familial ties (Hwang, 2009; Zhai, 2001). Within the small inner circle of guanxi, Chinese are collectivistic, and thus the principles of obligation and benevolence apply. Selfinterested behaviour in this context is viewed as immoral. Therefore, Hwang called the principles that apply to relationships in this category 'the rules of need' - a Chinese person should satisfy the needs of his (or her) familial ties according to the requirement of lun.

However, the concept of lun is not applied to only familial members. The most important five elements of lun also include loyalty between emperor and subordinates, and friendship. So in this article, familial ties will be captured in another term, 'pseudo-familial ties' (Chen, 1994), since they include patron-client, adoptive, and blood-brother relations (Luo, 2005).

The Chinese concept of familiar ties is characterized by a combination of instrumental and expressive ingredients (Yang, 1993). Each of these types of ties (i.e., pseudo-familial or familiar) creates unique opportunities for expanding social circles based on strong ties. Acquaintance ties are actually weak instrumental ties, which are akin to Uzzi's (1997) 'arms-length' or Williamson's (1996) 'spot market' transactions. Chinese tend to use familiar ties to refer to a strong instrumental exchange, such as a strategic alliance, joint venture, or long-term complex transaction. Chinese favour using familiar ties in these situations because strong personal trust can be built up through 'renqing fazei' (人情法则; the rules of favour exchange), an expectation that frequent exchanges of 
favours occur among one's circle of familiar ties (Hwang, 1987; Tsui \& Farh, 1997).

Chinese particularistic thinking introduces a different dynamic into familiar ties. 'The rule of favour exchange' guides these relationships and introduces a kind of quasi-collective behaviour. Members of such a group tend to imitate familial ties by meeting each other's needs without asking anything in return. Yet unlike familial ties, both parties understand that repayment is required. Thus, favour exchanges are not purely strong instrumental exchanges since they also involve some type of expressive meaning.

Both sides in a familiar tie want to introduce the moral code of sibling-like friendship into their relations. Chinese refer to this ethic as yi (in Chinese 義, the 'lun' among blood brothers or roughly 'brotherhood'). $Y_{i}$ requires that an actor does everything possible for a sibling, even sacrifice himself (or herself) if necessary. While exchanges of favours in familiar ties are a type of social exchange in which repayment is necessary, it has a particular characteristic. Like social exchanges in general, favour exchanges do not require instant reciprocation. The exact amount the person owes is difficult to measure and difficult to negotiate. However, there are some distinctions between favour exchanges and common social exchanges. First, under the yi ethic, almost anything may be exchanged, since a person ideally should do anything for a sibling. Second, according to the $y i$ ethic, a favour-giver must not say anything about the favour. Conversely the bao ethic would require the favour-taker to never forget the favour. Once the favour-giver clearly asks for a favour in return, then his or her help is no longer a favour. Third, favours are personally tailored. The favour could be a measure to give face to the other party or a service or product that will satisfy his or her current pressing needs.

Some favour-giving behaviours are legal and proper, such as introducing helpful friends, giving face-saving or face-giving behaviours, offering emotional support, suggesting helpful advice, and so on. But some other behaviours can be considered immoral, including privilege exchange, under-the-table trades, and unfair beneficial treatments.

Yang (1995) pointed out that strong and weak instrumental exchanges may coexist in any type of guanxi, regardless of whether it involves positive, neutral, or negative emotions. In other words, instrumental exchange is independent of the type of emotional involvement. Chinese do not necessarily make deep and wide exchanges based solely on strong ties; there are some types of guanxi that pair weak emotional involvement with strong exchange. Yang also argued that instrumental exchanges may reduce the level of friendship between two good friends, since the strategic bargaining and calculation of self-interests in the operation of instrumental exchanges may hurt the expressive feelings associated with pure friendship (Yang, 1995). The argument that instrumental exchange decreases expressive feelings is different from Hwang's concept of 'mixed ties', in which Chinese acquaintance ties are thought to lack the strength to facilitate critical instrumental 
exchanges, yet when upgrading an instrumental relation to a familiar tie (or a mixed tie in Hwang's term), it is necessary to increase emotional attachment.

Both Yang and Hwang's theories emphasized the importance of instrumental exchanges in guanxi, which parallels existing network theory. According to Granovetter (1973), tie strength can be measured by four factors - duration of relation, interaction frequency, intimacy, and reciprocal services. As a dimension of tie strength, reciprocal service indicates the importance of instrumental exchanges as the measurement of tie strength. Based on Hwang and Yang's common agreement on the importance of instrumental exchanges, we thus have an analytical framework of guanxi with two dimensions - expressive and instrumental dimensions.

According to Hwang's 'mix ties' concept, familiar ties developed from acquaintance ties should have a higher degree of expressive exchanges than acquaintance ties, since favour exchanges work only under the guise of friendship. Chinese often upgrade their expressive involvement before initiating favour exchanges with an acquaintance tie. The reason for this is that favour exchange is a long-term and intensive social commitment, so understanding the partner's willingness to reciprocate is a necessary step for a Chinese person to initiate exchanges. The common belief is that a loyal and benevolent person would generally want to return favours. However, if the partner's willingness to reciprocate is weak, then the opportunistic behaviours in favour exchanges will be costly. That is why, before establishing a long-term exchange relationship, Chinese people usually investigate a person's trustworthiness through word of mouth as well as conduct tests, such as favour exchanges.

Chinese people often invite real familial and pseudo-familial ties to engage in strong instrumental exchanges for a common interest. For instance, father-son, husband-wife, and brothers often become partners in Chinese family businesses. As noted, Yang (1995) opined that if pseudo-familial ties involve instrumental exchanges, the emotional attachment will decrease, since self-interest, rational calculation, and bargaining may decrease the expressive involvement between both sides in a pseudo-familial tie.

The two-dimensional model of guanxi is illustrated in Figure 1. The instrumental dimension is characterized by the norm of fair exchange, while the expressive dimension follows the strong moral requirement of 'need' and 'responsibility' (lun). In the lower left area of the quadrant is the acquaintance tie, which follows the rule of equity (fair exchange). The lower right area is the pseudo-familial tie, which focuses on the rule of need. Familiar ties are in the upper-middle area, which is a combination of these two types of relations, and a good fit for the moral code that balances bao and $y i$ - the rule of favour exchange. Thus, the first hypothesis follows:

Hypothesis 1: There will exist three types of ties in Chinese workplaces: pseudo-familial ties, acquaintance ties, and familiar ties. 
Figure 1. The two-dimension model of Chinese guanxi

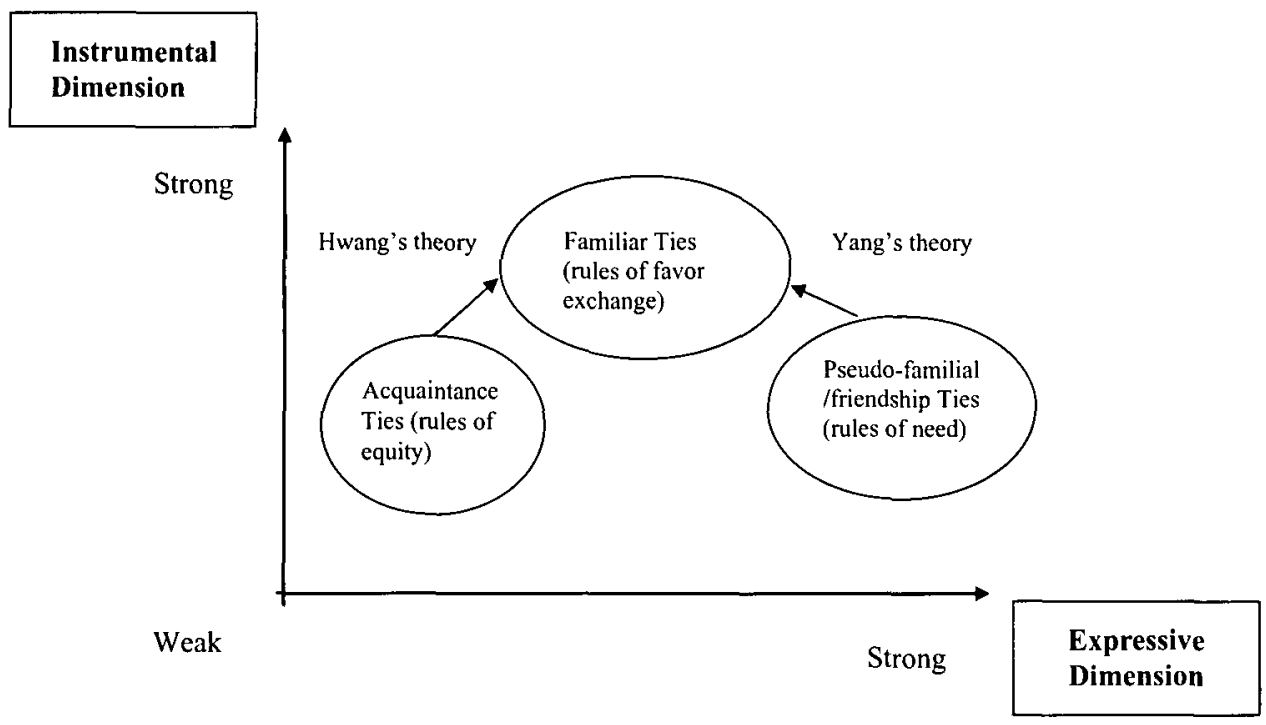

Hwang proposed that familiar (or mixed type) ties developed from acquaintance ties are placed midway along the $x$-axis. Since these ties have more instrumental exchanges (under the rules of favour exchange), it leads to stronger emotional expression than in the case of acquaintance ties. On the other hand, Yang illustrates that increasing instrumental exchanges decreases the emotional involvement of pseudo-familial ties. Thus, strong instrumental ties that lack an expressive component and strong expressive ties that have a strong instrumental component are absent from the upper-left and upper-right corners of the model, respectively.

\section{Trust in the Three Types of Guanxi Ties}

Do familiar ties carry as much trust as pseudo-familial ties? Moreover, is trust embedded in familiar ties greater than in the other two types of ties? If the answer is yes, then Chinese will not constrain their complex transactions within the small circle of pseudo-familial ties.

Emancipation theory (Yamagishi, Cook, \& Motoki, 1998; Yamagishi \& Yamagishi, 1994) would argue that assurance is bred from pseudo-familial ties because the members of a small closed group can monitor each other's behaviours. A major distinguishing feature of trust versus assurance is the risk of exploitation by others. For example, trust in general is based on moral expectations that people universally will extend goodwill and reciprocate without risk of exploitation. In societies based on low trust, various formal laws or regulations and informal social sanctions exist 
to minimize the uncertainty of exploitation. Low-trust societies depend on these legal and extra-legal means of building up assurance that exploitation will be minimized.

Additionally, trust may be invested in particular individuals. It is easier to trust a specific person than people in general. Personal trust - based on the expectation of a specific person's goodwill - may be built up through characteristic-based means. Individuals may minimize risks of exploitation by focusing on personal traits, emotional states, or role-identities, all of which can give the appearance of trustworthiness (Butler \& Cantrell, 1984; Zucker, 1986). For example, most individuals assume that policemen are more trustworthy than criminals. Calm individuals are more trustworthy than highly excitable people, as well as someone who appears tolerant is more trustworthy than an intolerant person. Similarly, we trust people who behave consistently and openly rather than inconsistently and secretively. These assumptions draw on the roots of classic balance theories of cognitions (Heider, 1958).

Assurance-based societies, however, depend on the use and abuse of power to decrease risk. Signs of assurance and low trust include indicators such as the employment of hostage taking (Cook, Eric, \& Alexandra, 2004), the use of legal documents like contracts, and the development of personal commitments based on short-term economic exchange rather than generalized exchange. According to Yamagishi and Yamagishi's (1994) emancipation theory of trust, assurancebased societies do not allow realistic alternatives to be present in exploitative relationships. Individuals in a small circle of pseudo-familial ties usually find themselves webbed in a similar kind of community. Social relations within pseudo-familial ties induce both sides to behave reliably; however, this behaviour does not necessarily imply a high level of trust (Cook, 2004). By contrast, hightrust societies are marked by realistic alternatives to exploitation such as leaving the job (turnover), leaving a family (divorce), or changing social clubs, etc. Such realistic alternatives, in fact, increase trust since members of groups and organizations understand that exploitation may lead to the dissolution of a valued relationship.

Although the small circle of familiar members reflects the characteristics of assurance-based societies, the Chinese still think of these ties as among their most trustworthy relationships (Wang \& Liu, 2003). Strong expressive involvement deeply influences the sense of trustworthiness. A hypothesis first developed in the U.S. (Krackhardt, 1992) states that strong ties among intimates is most likely to produce trust, as compared to weak ties like arms-length business relationships (Uzzi, 1997).

In the category of acquaintance ties, trust can be bred through the Chinese concept of bao, which parallels Blau's (1964) social exchange theory. As Blau argues, a person engaging in social exchanges, unlike economic exchanges, cannot expect instant rewards. They must believe in the goodwill of the other party, which 
will result in future reciprocity. Blau notes that long-term, repeated exchanges foster mutual trust.

However, trust of acquaintances is so weak that it is insufficient in obtaining certain valuable resources such as introduction to a key person, passing on vital information, or conducting a risky deal. This is why Chinese people often work to shift reliable and frequent exchange relations into the category of familiar ties. Familiar ties are a key to obtaining important resources for economic transactions, especially since these ties are strong enough to be a bridge to other guanxi needed by the focal actor.

The Chinese concept of $y i$ describes the friendship of blood brothers, and has the social function of making familiar ties serve the needs of both parties. To betray a close friend is considered grossly unethical behaviour, and results in the conscientious condemnation of betrayers. Thus the concern about friendship helps to make behaviours in such relationships reliable.

In addition to these social restraints, favour exchanges are also rational, and each side is required to demonstrate trustworthy behaviour. Unlike pseudo-familial ties, familiar ties can be easily broken if trustworthy behaviour is lacking. The main characteristic of these relations is that these favours require payback. To this end, both parties maintain a 'favour account' to remember who they owe favours to and be ready to repay those favours when an opportunity arises. This is the principle of $b a o$, or reciprocity, that I described earlier. The need for trustworthy behaviour, along with norms for keeping friendship, suggests that such ties are characterized by a high level of trust.

The negative features of trust in Chinese societies are that ties are based more often on personal relationships than general institutions. The positive features are that the risks of exploitation of less powerful members of dyads may be muted by norms. These norms encourage benign behaviours among members of the brotherhood and lead to feelings of trust and trustworthiness. Thus, familiar ties appear to increase a sense of personal trust among the least powerful members of asymmetric dyads (who are most at risk of exploitation). Summarizing the discussion above, I thus propose a second hypothesis:

Hypothesis 2: Familiar ties will contain a higher level of trust than pseudo-familial ties or acquaintance ties.

\section{METHOD}

This article theorizes that familiar ties are the third type of ties in addition to pseudo-familial and acquaintance ties. First, I developed items to measure certain types of relational contents a priori. Then through factor analysis, I tested a measurement model where I posit that different relationships (e.g., mediating friends and mutual sharing guanxi) are empirical indicators of the abstract concept 
of familiar ties. I finally used regression analysis to assess the level of trust associated with each type of ties.

\section{Measures}

To explore the relationships among the different dimensions of guanxi discussed above, I used questions about several types of relationships to model whole networks among employees in a single firm. In order to measure pseudo-familial ties that are expressive and based on the rules of need, I asked questions about friendship among workers. To identify acquaintance ties that are instrumental in nature and based on rules of equity, I asked about information exchange and advice among workers. Regarding relationships that are familiar and based on rules of favour exchange, I asked questions about guanxi that mediate relationships or where within relationships one would lend money or share ideas. For a measure of trust, I asked a series of questions to measure the honesty, consistency, loyalty, and benevolence of fellow workers.

Three types of ties have been studied in workplaces, i.e., friendship, advice, and communication ties (Krackhardt, 1992; Krackhardt \& Hanson, 1993). Among them, friendship is the indicator for pseudo-familial ties, which continue for its own sake, such as friendship, love, passion, and identity. If and only if a question is related to intimate friendship behaviours, it will be included in this category (Luo, 2005). They thus can be identified as pseudo-familial/friendship ties in the settings of workplace settings. These questions are listed as the first to fifth items in the Appendix. Sample items include: 'I am involved in social activities (like shopping, dining, etc.) with him or her after work.' 'With whom do you talk about your private affairs during your daily chats?'

Advice and communication ties are measured for acquaintance ties, since they are instrumental and play certain functions for an actor. Know-how obtained from collegial consultations is generally the cornerstone of doing a good job (Granovetter, 1992). Social ties are important for transferring such know-how, improving efficiency, creating cooperation, and smoothing business processes in the workplace (Baker, 1994). Network theorists have also successfully linked information sharing to the strength-of-weak-ties thesis (Granovetter, 1973). Early studies of job matching in network theories have shown strong evidence that a person participating in many weak ties may have an information advantage and thus obtain better jobs (Granovetter, 1974). A relational web that enables a person to obtain the right information at the appropriate time provides a foundation for business opportunities (Burt, 1992). Non-redundant information is more likely to be a by-product of weak ties, rather than intimate relations.

In addition, in my preliminary qualitative study of communication networks in Chinese workplaces, I found that the most common information flow among office acquaintances is related to two daily discussion topics. One is gossip about other 
office mates' private lives and business. It is important for a worker to recognize the network structure in his/her office. The other topic is related to daily life, such as shopping, dining, recreation, etc. The social ties that exist in group social discussions involve, more or less, some type of expressive meaning, but are not necessarily friendship ties.

The questions related to acquaintance ties are the sixth to eleventh items in the Appendix. Two sample items include: 'If I have confidence in a product, I will introduce it to him or her.' 'Who may actively come to help you when you encounter difficulty in your job?' All the 'helps' listed in the six questions are not difficult to offer, so they can be provided by acquaintance in Chinese workplaces.

The questions concerning intimacy in friendship are indicators of pseudofamilial/friendship ties, and those related to weak instrumental exchanges are indicators of acquaintance ties. Two types of reciprocal services are especially important for a Chinese, and only familiar ties can meet those needs. One is 'mediating friends' and the other is 'mutual sharing' (Zhai, 2001, 2005).

'The rule of need' is only the principle of lun - the moral codes for pseudo-family members, and the principle of ' $y i^{\prime}$ can be applied for familiar ties as stated above. In practical operations of this principle, Chinese people seldom satisfy all the needs of familiar ties. Instead, a Chinese person shares everything he (or she) owns, more or less, with familiar ties. Both familiar and pseudo-familial/friendship ties are called 'good friends' by Chinese, but the former involves a more instrumental purpose while the latter continues for its own sake. So the indicators of this category of ties ask questions related to strong instrumental exchanges, rather than intimate behaviours, but these instrumental exchanges are too strong to be provided by acquaintance ties.

Two kinds of mutual services represent this sharing principle in my questionnaire. The 'I am willing to lend 1 month salary or more to him or her' question indicates a propensity to share financial property. The 'I am willing to share a new idea with him or her' question indicates a propensity to share intellectual property.

The third is the sharing of friends. 'Mediating friends' is the most important process through which a Chinese person can meet new 'friends'. It also assists in building up a minimum level of trust with them, and sets the conditions to engage in transaction exchanges. 'Mediating' has two functions. First, a middleman must play the role of conciliating the dispute between the two sides. Second, if opportunistic behaviours occur, the middleman becomes a safeguard and may take responsibility for compensating the loss of the other side. Without strong trust, few Chinese would wish to take such a heavy responsibility. I designed two questions to represent friend-mediating relations. These questions are 'If he or she asks, I would be willing to help his or her friends' and 'I am willing to introduce him or her to my friends'.

Finally, I measure trust. Butler and Cantrell (1984) identify five dimensions of managerial trust. The authors rank cognitive traits based on the importance of the 
partner's perceived: (i) competence; (ii) integrity (involving reputation and honesty); (iii) consistency (or reliability and predictability); (iv) loyalty; and (v) openness (Butler, 1991). Mishra (1996) focused on the connection of trust and trustworthiness. He suggested that trust involves taking risks based on the conviction that the other party is trustworthy. Often, the other party possesses four important traits: (i) competence; (ii) honesty (which assumes open); (iii) benevolence (which assumes concern); and (iv) consistency (which assumes reliable). I chose loyalty and benevolence to model trust as they are related to maintaining relations (see questions 18 and 19 in the Appendix). I selected honesty and consistency to measure trust in the partner's characters (questions 16 and 17). In addition, I added question 20 as an overall indicator of trustworthiness.

\section{Procedure: Collecting Whole-Network Data}

The data were collected from a China-based factory of a Taiwanese high-tech company. The company is a global leader in the manufacturing of computer peripheries and mobile phones. I distributed 498 copies of the questionnaire in 19 departments.

In the questionnaire shown in the Appendix, the first row lists all the members' names within the department. The first column lists all 20 questions to measure 15 different guanxi items and five trust items. The survey team visited each department to provide instructions on filling out the survey. All members in the department office were asked to complete the questionnaire on the spot. The respondents were instructed to put a check ' $\checkmark$ ' in the cell of each member of their department with whom he/she had social relations. For example, the first question was related to social activity with 'Member $Z$ '. A ' $\sqrt{ }$ ' would mean the respondent and ' $Z$ ' have social-activity ties, while a 'blank' indicated no such ties.

Some workers were not in the office when we surveyed the department, and some refused to answer, but all the departments had a response rate above 80 percent. After excluding invalid and incomplete answers, we obtained a total of 414 valid responses, with a response rate of 83.1 percent. Six departments had several members who chose not to answer some questions. Because of the lack of complete information within these six departments, we decided to discard these departments' data in order to prevent distortion of structural variable indicators. At the end of the survey, we had a total of 13 departments with 310 persons for our analysis.

This questionnaire also includes several demographic variables. A ' 0 ' indicates malc and a ' 1 ' female for measuring gender. Age is reported as number of years. For marital status ' $O$ ' means unmarried while ' 1 ' signifies married. I measure educational level with a five-point scale, in which ' 1 ' signifies below high school, '2' equals high school, ' 3 ' stands for college, ' 4 ' equals university, and ' 5 ' means graduate school. Position includes four ranks, in which ' 1 ' is general staffs, ' 2 ' 
means engineers, ' 3 ' indicates low-rank managers, and ' 4 ' indicates high-rank managers. The number of months working in this company is surveyed for tenure.

In the samples, 54.9 percent are male, average age is 26.4 years old, only 26.7 percent are married, and the mean of education level is high, nearly university level. On average, the sampled employees have worked in this company for 27.3 months.

\section{Analyses}

I employed factor analysis to identify the structure of the 15 guanxi and 5 trust items. First, I combined the data of all departments into one large data set. ${ }^{[1]}$ The data structure is specified as in the Appendix, in which the columns correspond to the 20 relational items and rows are all 7,714 pairwise relations in all the departments. ${ }^{[2]}$

This data model's weakness is that most of the cells are 'blank', since a respondent may generally check ' $\checkmark$ ' for only a few members and ignore most other names listed on the questionnaire. The larger the department is the higher proportion of blank answers appears in the model. The correlation among the 15 guanxi items and five trust items are thus distorted. To reduce the influence of 'blank' answers, I recoded the column data with all blank answers for the 15 guanxi items as missing. As a result, 3,890 pairwise ties were dropped leaving 3,824 for analyses.

I then randomly sampled half of the valid data, i.e., 1,911 ties, and conducted an exploratory analysis. The analysis will depict how many factors can be found among the 15 guanxi and 5 trust relations. Since I only have binary data, tetrachoric correlations will be computed instead of Pierson correlations. I then take the tetrachoric correlation matrix as input for the factor analysis.

Third, I conducted analysis of the remaining portion of ties, i.e., 1,913 ties, using confirmatory factor analysis. A Structural Equation Model (SEM) was used to test the validity of the factor structure.

Finally, I created a binary variable of trust which I will describe below, and performed a logistic regression, regressing trust on all types of guanxi, using the combined data set. I included a set of demographic variables, such as gender, age, marital status, education level, position, and tenure, as controls. Through this method, I tested whether familiar ties have a stronger relationship to trust than pseudo-familial/friendship ties and acquaintance ties.

\section{RESULTS}

\section{The Factor Analysis of Guanxi items}

Table 1 shows the results of our exploratory factor analysis. I used the Principal Component Analysis for extraction method and Varimax for rotation method. 
Table 1. Exploratory factor analysis results of the 15 guanxi items and 5 trust items

\begin{tabular}{lllll}
\hline \hline & \multicolumn{4}{c}{ Component } \\
\cline { 2 - 5 } & 1 & 2 & 3 & 4 \\
\hline & & & & \\
Q1 & 0.31 & $\mathbf{0 . 5 6}$ & 0.23 & 0.03 \\
Q2 & 0.33 & $\mathbf{0 . 5 8}$ & 0.24 & 0.15 \\
Q3 & 0.22 & $\mathbf{0 . 8 4}$ & 0.21 & 0.35 \\
Q4 & 0.21 & $\mathbf{0 . 7 9}$ & 0.14 & 0.26 \\
Q5 & 0.36 & 0.45 & 0.36 & 0.18 \\
Q6 & 0.45 & 0.33 & 0.48 & 0.26 \\
Q7 & 0.24 & 0.34 & $\mathbf{0 . 5 5}$ & 0.27 \\
Q8 & 0.27 & 0.34 & 0.24 & $\mathbf{0 . 5 9}$ \\
Q9 & 0.27 & 0.35 & 0.35 & $\mathbf{0 . 5 2}$ \\
Q10 & 0.25 & 0.18 & 0.33 & $\mathbf{0 . 7 2}$ \\
Q11 & 0.28 & 0.19 & $\mathbf{0 . 6 4}$ & 0.14 \\
Q12 & 0.20 & 0.20 & $\mathbf{0 . 7 9}$ & 0.34 \\
Q13 & 0.18 & 0.23 & $\mathbf{0 . 7 3}$ & 0.16 \\
Q14 & 0.29 & 0.18 & $\mathbf{0 . 6 5}$ & 0.12 \\
Q15 & 0.32 & 0.18 & $\mathbf{0 . 6 4}$ & 0.26 \\
Q16 & $\mathbf{0 . 6 4}$ & 0.23 & 0.49 & 0.17 \\
Q17 & $\mathbf{0 . 6 7}$ & 0.33 & 0.30 & 0.25 \\
Q18 & $\mathbf{0 . 6 4}$ & 0.36 & 0.35 & 0.25 \\
Q19 & $\mathbf{0 . 7 8}$ & 0.31 & 0.30 & 0.20 \\
Q20 & $\mathbf{0 . 8 1}$ & 0.30 & 0.29 & 0.25 \\
\hline \hline
\end{tabular}

Note: The bold numbers indicate the component found in the exploratory factor analysis.

Please refer to the Appendix for descriptions of the 20 questions. Component $I$ = trust, II = pseudo-familiar/friendship ties, III = familiar ties, $I V=$ acquaintance ties.

The initial eigenvalue for extracting the four components is 0.96 , and the cumulative explained variance is 72.38 percent. Questions 5 and 6 have too low of a loading (below 0.5) to be included in any of the components; therefore I take them as outliers and deleted the items. The loading on the four factors correspond to our expectations. Questions 1-4 are included in the second component, which can be viewed as associated with pseudo-familial/friendship ties. Questions $8-10$ form the fourth component and they could be viewed as associated with acquaintance ties. Questions 7 and 11-15 were classified in the third component and measure familiar ties, and questions 7 and 11 were originally intended to reflect acquaintance ties. Questions 16-20 form the first component, which can be referred to as trust. The exploratory factor analysis identified the three types of guanxi.

To confirm the validity of the results, a confirmatory factor analysis was conducted. I use the remaining data to test the model. Figure 2 shows the SEM model 
Figure 2. The confirmative factory analysis on guanxi and trust

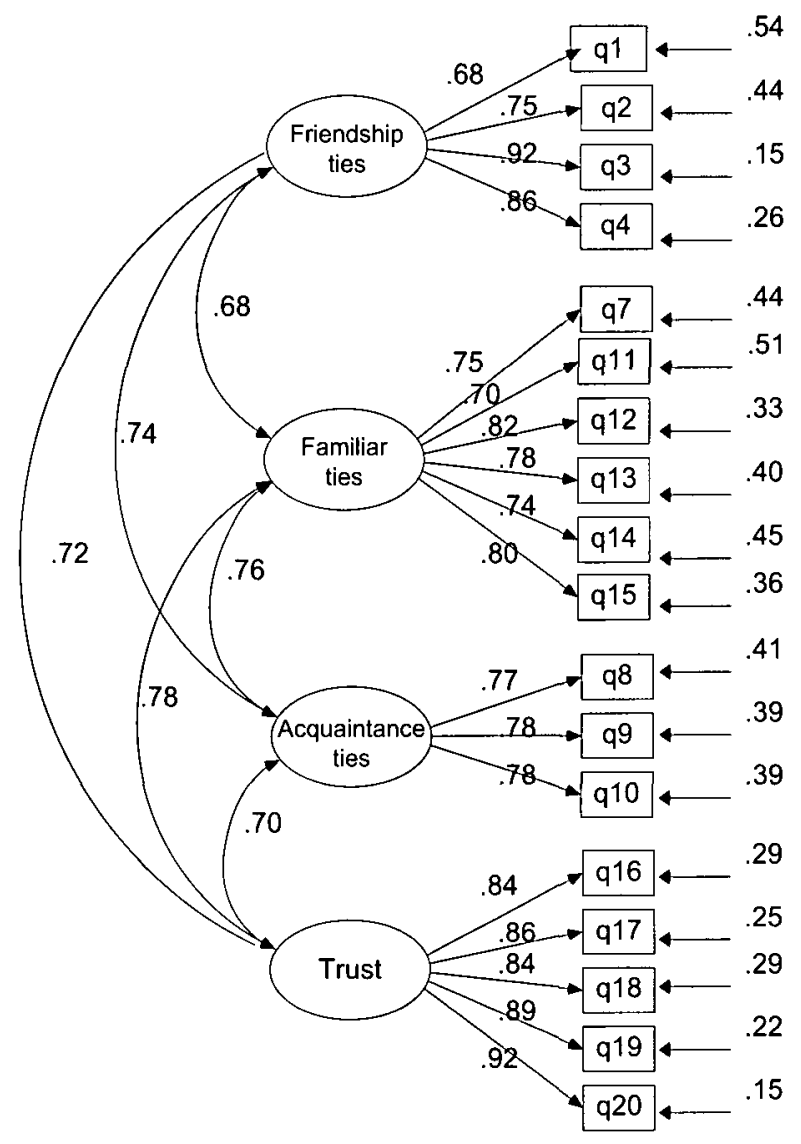

used in our analysis. All the indicators of model fit illustrate positive results: CFI is 0.91, RMR is 0.05, RMSEA is 0.098, AGFI is 0.91, and NFI is 0.91. Only one indicator is exceptional. $\chi^{2}$ is $3,087.94$ and $p$ value is less than 0.001 . This result is not that surprising considering the large size of our data set. This supports my first hypothesis.

To test the correlation between guanxi and trust, I again use the ordered pair as the unit of analysis and averaged the four items of friendship relationship to get a single index of pseudo-familial/friendship tie for each ordered pair. I did the same computations for familiar ties, acquaintance ties, and trust. The mean of trust is 0.376 . I thus created a binary variable of trust, in which ' 0 ' indicates low trust with a score below 0.376 , and ' 1 ' means high trust with a score above the average. As a result, 45.9 percent of ordered pairs are classified as high trust. I then used all of the 3,824 ties to compute the correlations among these single indices. The results are listed in Table 2. 
Guanxi, Familiar Ties, and Trust

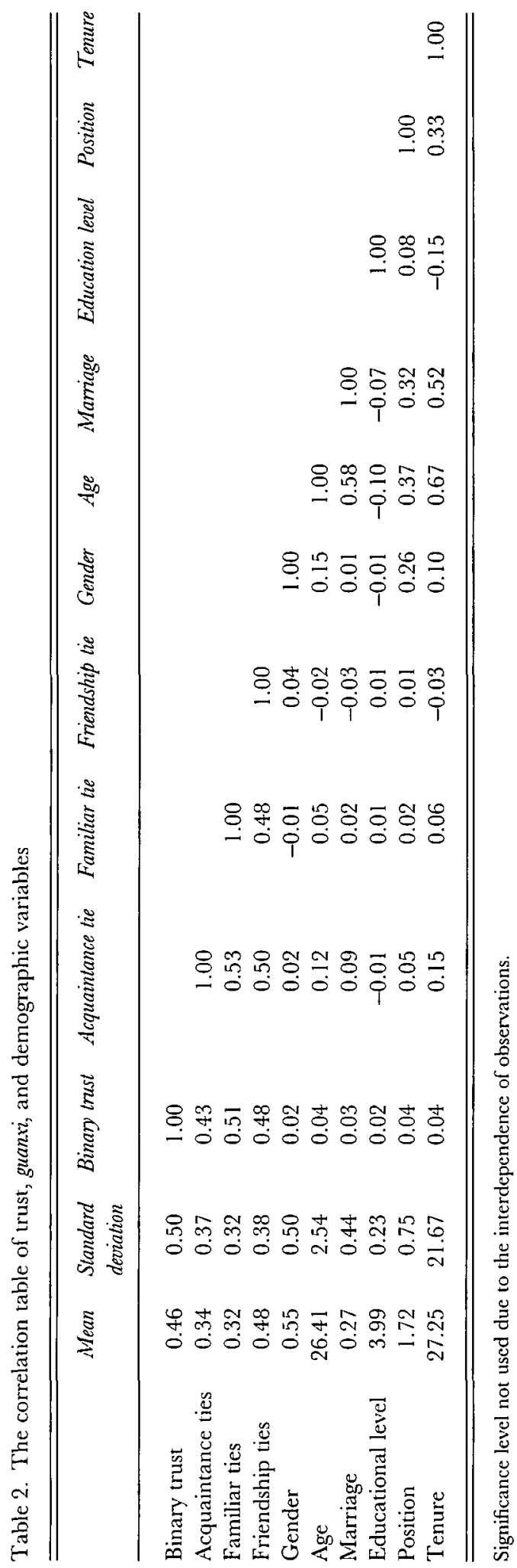

(C) 2011 The International Association for Chinese Management Research 
Table 3. Logistic model regressing trust on guanxi and controls

\begin{tabular}{lcc}
\hline \hline Dependent variable: trust & Centralized coefficients & Centralized coefficients \\
\hline Gender & 0.040 & 0.025 \\
Age & 0.009 & 0.000 \\
Marital status & -0.005 & 0.042 \\
Education level & 0.216 & 0.180 \\
Position & 0.058 & 0.063 \\
Tenure & 0.003 & 0.001 \\
Friendship tics & & 1.866 \\
Familiar ties & & 2.858 \\
Acquaintance ties & 260.47 & 1.023 \\
Pearson Chi-Square & 0.003 & $3,063.26$ \\
Cox and Snell Pseudo-R-Square & 3,824 & 0.329 \\
$\mathrm{~N}$ & & 3,824 \\
\hline \hline
\end{tabular}

Significance level not used due to the interdependence of observations.

Finally, I centralized all guanxi and control variables. ${ }^{[3]}$ I then create a logistic regression model, regressing the binary variable of trust on all centralized guanxi variables and controls. The results are shown in Table 3.

In Table 3, I do not report significant tests due to the problem of interdependence of observations, i.e., the ordered pairs (or dyads) are not independent of each other ${ }^{[+]}$However, this will not affect my conclusion, since my interest is the comparison among guanxi variables. The results show that all control variables have a very minor effect on explaining trust. The Cox and Snell Pseudo-R-Square is as low as 0.003 . This number rises to 0.329 after adding the three guanxi variables into the logistic model. It is guanxi that explains the biggest part of trust relations. Familiar ties are most likely to increase the probability of being in a high trust relationship, i.e., $(b=2.858)$, in comparison to pseudo-familial/friendship ties $(b=1.866)$ and acquaintance ties $(b=1.023)$. The second hypothesis may be considered as confirmed too.

\section{DISCUSSION}

The data analyses stated above reach several conclusions. First, familiar ties indeed exist in a two-dimensional framework of guanxi. Second, familiar ties involve no less trust than pseudo-familial/friendship ties and perhaps more. That means both familiar and pseudo-familial/friendship ties can be taken into the inner circle in terms of trust, which is the mediator between social relations and economic actions (Granovetter, 1985).

This result is not surprising, since familiar ties are built upon long-term exchanges under the name of 'brotherhood'. On the one hand, trust can be bred through trustworthy behaviour in repeated exchanges that are based on mutual 
self-interest (Hardin, 2001). In other words, trust is the result of fair exchanges, in which both sides demonstrate trustworthy traits. Honesty, consistency, benevolence and loyalty behaviours are all examples of trustworthy traits (Butler \& Cantrell, 1984; Mishra, 1996). This fact allows for the exchange relationship to continue.

On the other hand, long-term fair favour exchanges breed friendship. The operational art in familiar ties is to balance instrumental and expressive motives, so that trust can be maintained in a high level. As Granovetter puts it:

So individuals have some reason to be continuously scanning relationships to determine the balance of motives [consummatory or instrumental] behind them. One reason this is difficult, aside from instances of clever deception, is that even relationships that begin for obviously instrumental purposes, if they continue for any period of time, become overlaid with affective social content of the kind that I have described as consummatory - where part of the reason for maintaining the relationship becomes the value of the interaction itself (Granovetter, forthcoming)..$^{[5]}$

On the contrary, the circle within pseudo-familial ties is rather small and closed, and the norm within the circle is strong. The principle of lun is a very strong norm. The whole family and community within pseudo-familial ties will condemn anyone who breaks that norm. The norm lun requires some form of collectivistic behaviour. Pseudo-family members should satisfy the needs of other members without asking for any type of compensation in return. Due to the monitoring that is characteristic of such a close group, social interaction within this type of social circle is predictable and often reliable. Yamagishi and Yamagishi (1994) refer to this phenomenon as 'commitment' relations (Yamagishi et al., 1998), where 'trustworthy' behaviour is due to the monitoring and sanctioning of strong norm and risk is minimized (Yamagishi et al., 1998; Yamagishi \& Yamagishi, 1994).

Based on these findings and existing theories, it is possible to obtain a hypothetical model explaining how Chinese people are able to conduct complex transactions with strangers in the global economy. We can speculate that Chinese indeed tend to make complex deals within a closely knit group of people; however, the scope of this inner-group may indeed be quite broad. They may search for business partners among strangers worldwide, and then upgrade these useful relations gradually. At the very beginning, a third party may introduce a stranger into a person's network. This relationship will be based on acquaintance ties with the focal person. After conducting a series of business transactions and social exchanges to test each other's trustworthiness, the focal person may allow for more of an expressive element to develop within this relationship. Eventually, the acquaintance tie becomes a familiar tie, where there is an expectation for securing promises in long-term, frequent, and complex transactions. 


\section{Limitations}

There are several limitations that make our quantitative study insufficient. First, the sample is not diverse. Data collected from one hi-tech company can only be treated as a typical example of hi-tech firms. More work is required, however, before these hypotheses can be completely confirmed. We need more data from different types of firms to check these hypotheses.

Second, the study focuses on organizational behaviours in workplaces. As stated above, the research design results in cases being clustered in departments, making it difficult to distinguish different types of guanxi. Although this study still validly identifies three types of guanxi, it is necessary to collect data in areas other than a single large organization in order to confirm the results of our factor analysis. For example, studies of entrepreneurs would be fruitful since they may invite pseudofamilial members to be business partners and also need to upgrade acquaintance ties into the inner circle. It is possible to find more types of guanxi in research on entrepreneurs.

Third, I do not have a valid measurement of the communication network. Could it be that communication relationships are not merely instrumental ties, but rather are more or less involved with expressive meanings? If so, is there another type of mixed tie that could capture the characteristics of a tie that has less instrumental and expressive ingredients than what we already know as familiar ties in Chinese society? How do we design good measures of them? These questions pose some unique challenges to future studies.

Lastly, developing better and more diverse measurements related to familiar ties deserves attention. Many valid and reliable measurements exist in the categories of instrumental exchange and expressive social relations. However, few studies seek to measure familiar tie in whole-network surveys. I designed four questions related to two types of favour exchange, far fewer than what we consider to be sufficient. Future studies should explore more types of favour exchange and develop corresponding ways to measure them.

\section{Future Research Implications}

The hypothetical mechanism is actually based on Hwang's theory, in which Chinese often upgrade the expressive involvement before upgrading instrumental exchanges with an acquaintance. We can postulate that such familiar ties are still in reality instrumental, thus self-interest and calculative rationality are central elements in this category. This type of familiar ties 'pretends' to be sibling-like friends, but in actuality, this is not the case. The indigenous Chinese concept of bao (reciprocation) is applied to this type of ties, and is a highly appreciated basis of morality in China (Zhai, 2001). Returning favours is an obligation expected by most Chinese people. Accepting favours but forgetting to return them is likewise 
shameful. $Y_{i}$ requires one to provide favours - important and personally tailored acts of assistance - for the partner, but bao requires that these favours be returned.

Which of Hwang's theory or Yang's theory is correct? Or, whether both are correct is a good question for future studies. For instance, if both theories are correct, that would mean that real familial and pseudo-familial ties may involve strong instrumental exchanges. A good example of this is the joint investment by blood brothers to run a business. In addition, family businesses often involve the joint investment of a husband and wife, father and son, or brothers. By definition, these relations are both expressive and instrumental. This type of relation may be seldom seen among organizational employees, but is common in Chinese society. What are the rules that govern the interactions in these relations? What is the difference between the pseudo-familial ties of this sort and familiar ties? More qualitative studies are necessary to explore these questions.

Distinguishing familiar ties from the most inner circle makes Chinese open to larger social network. Familiar ties may be developed with any person, but it requires a long-term dynamic process to build high level of trust in order to make complex transactions possible. It is found that Chinese are good at balancing coupling and decoupling, and that is why overseas Chinese are successful in the business area (Granovetter, 1995). Structural holes can seek opportunities, while closed groups can provide strong base of social capital to seize the opportunities. A successful entrepreneur needs to couple structural holes and closed groups (Granovetter, 2002). The institutions of familiar ties may be the clue to explain this observation. How Chinese entrepreneurs couple closure and structural holes poses great challenges to future indigenous management studies.

Closure, long-term employment and merging of work and non-work relationships are often thought as the features of Eastern Asian model of firms (Chai \& Rhee, 2010). Chinese are often thought of as a familial-collectivism society (Chua, Ingram, \& Morris, 2008), in which workplace is taken as an extended family (Chua, Morris, \& Ingram, 2009). Closed, dense, and intimate guanxi network in workplace should result in collective cohesiveness (Balkundi \& Harrison, 2006) and organizational identification (Sluss \& Ashforth, 2008), and thus encourage organizational loyalty. However, there is strong evidence in the employee turnover rates to suggest that this is not the case in Chinese firms. The annual turnover rate in manufacturing sectors was about 1.2 percent to 1.5 percent in Japan from 2006 to 2010, in comparison to 26 percent to 35 percent in the U.S. That number in China was about 16 percent to 22 percent. Taiwan, another Chinese society, evidenced even higher turnover rate, ranging from 28 percent to 40 percent in various areas, during the period of 2000 and $20011^{[6]}$

Chinese organizations are not as 'closed' as predicted in the East Asian model (Chai \& Rhec, 2010). How do familiar ties make Chinese firms open to larger social 
networks? How do various types of guanxi and the structure of social networks operate in Chinese firms? These questions deserve our investigation.

\section{CONCLUSION}

In a society with strong governing institutions that lower transaction costs, people may make complex exchanges with any acquaintance based on institution-based trust (Zucker, 1986). However, Chinese society is definitely not yet conducive to this type of exchange. In a society based on a framework of differential association, people in general choose instrumental exchange partners according to the degree of familiarity. As a result, familiar ties are the most important guanxi relations for doing complex transactions.

\section{NOTES}

This rescarch is supported by Taiwan's NSC for financial support via Projects NSC93-2412-H-007003 and NSC91-2416-H-155-014. I thank Anne Tsui and Mark Granovetter's comments on the previous versions of this paper. I am especially appreciative of Joe Galaskiewicz for his methodological suggestions which greatly improved the analysis of this paper.

[1] The 13 departments had $32,26,35,37,22,21,24,22,14,16,19,26$, and 16 persons separately. Each department has ties with $N(n-1)$, i.c., $992,650,1190,1332,462,420,552,462,182,240$, 342,650 , and 240 in the 13 departments. In total there are 7,714 ties in the final data set.

[2] These cells contain dyadic data (0 or l) listing from Respondent 1's relation with Respondent 2 in the first department to Respondent 16's relation with Respondent 15. Please refer to the Appendix.

[3] The correlations among the three guanxi items are $0.481,0.502$, and 0.532 , respectively.

[4] The same person reports on several ties, and two people are reporting on the same tie, each from their own point of view. Thus ties are not independent of each other, and the data on ordered pairs are not independent observations. For example, person $A$ in the first department with 32 employees reported 31 outward ties, and these 31 data points are not independent of each other, since they have common factors. This problem does not affect the coefficients and only the standard errors. So the coefficients are correct, but the $\mathrm{p}$ value and significance test will be distorted. That is why $\mathrm{p}$ values and significance tests are not reported. The differences among the three coefficients in the regression model are large enough to draw at least tentative conclusions.

[5] From Granovetter's forthcoming article 'Trust' in Chapter 3 of the book Society and Economy. I appreciate the special permission of the author to let me cite the book.

[6] Chinese data was attained from survey reports released by $5 \mathrm{ljob.com}$. U.S. data were attained from 'United States Department of Labor Bureau of Labor Statistics', and the website is http://www.bls.gov/data/. Japanese data were gained from 'Ministry of Health, Labour and Welfare', and the website is http://www.mhlw.go.jp/english/database/db-l/index.html. Taiwanese data come from a survey of 5,169 manufacturing factories in Census Bureau Employment Movement Survey (EMS) data sets, collected by the Directorate-Gencral of Budget, Accounting and Statistics (DGBAS) in Taiwan. 


\section{APPENDIX}

\section{The whole-network questions}

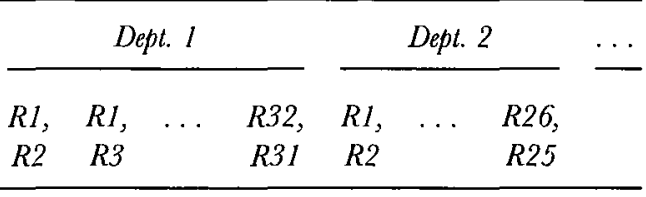

1. I am involved in social activities (like shopping, dinning, etc.) with him or her after work.

2. After being criticized by your employer, from whom do you seek emotional support?

3. I will keep contact with him or her even after I turnover.

4. With whom do you talk about your private affairs during your daily chats?

5. Who can be listed among your best friends?

6. If I have confidence in a product, I will introduce it to him or her.

7. I will gossip with him or her, talking about other officemates' private life and business.

8. When you encounter difficulty in your job, from whom do you ask help?

9. With whom do you like to discuss your daily work?

10. Who may activcly come to help you when you encounter difficulty in your job?

1I. Whenever I learn new knowledge concerning jobs, 1 would like to teach him or her.

12. I am willing to lend my I month salary or more to him or her.

13. I am willing to share a new thought with him or her.

14. If he or she asks, I would like to help his or her friends.

15. I like to introduce him or her to my friends.

16. I think that he or she is honest.

17. I think that his or her behaviour is stable.

18. I think that he or she will keep his or her commitment to me.

19. I think that he or she is concerned about my interests.

20. Who are the most trustworthy persons? 


\section{REFERENGES}

Baker, W. E. 1994. Netzorking smart. New York: McGraw-Hill, Inc.

Balkundi, P., \& Harrison, D. 2006. Ties, leaders, and time in teams: Strong inference about network structure's effects on team viability and performance. Academy of Management Joumal, 49(1): 49-68.

Blau, P. 1964. Exchange and pozer in social life. New York: Wilcy.

Burt, R. 1992. Structural holes: The social structure of competition. Cambridge: Harvard University Press.

Butler, J. 1991. Toward understanding and measuring conditions of trust: Evolution of a condition of trust inventory. Joumal of Management, 17(3): 643-664.

Butler, J. K., \& Cantrell, R. S. 1984. A behavioral decision theory approach to modeling dyadic trust in superiors and subordinates. Psychological Reports, 55: 19-28.

Chai, S.-K., \& Rhce, M. 2010. Confucian capitalism and the paradox of closure and structural holes in East Asian firms. Management and Organization Revieze, 6(1): 5-29.

Chen, C. H. 1994. Subcontracting networks and social life. Taipei: Line-Jin Press.

Chen, C. C., Chen, Y. R., \& Xin, K. 2004. Guanxi practices and trust in management: A procedural justice perspective. Organization Science, 15(2): 200-209.

Chua, R., Ingram, P., \& Morris, M. 2008. From the head and the heart: Locating cognition and affect-based trust in managers' professional networks. Academy of Management Joumal, $51(3): 436-452$.

Chua, R., Morris, M., \& Ingram, P. 2009. Guanxi vs networking: Distinctive configurations of affectand cognition-based trust in the networks of Chinese vs American managers. Journal of International Business Studies, 40(3): 490-508.

Cook, K. S. 2004. Network, norms and trust: The social psychology of social capital. Keynote Speech in Cooley Mead Award.

Cook, K. S., Eric, R. R., \& Alexandra, G. 2004. The emergence of trust networks under uncertainty: The case of transitional economies - Insight from social psychological research. In S. R. Ackerman, B. Rothstein \& J. Kornai (Eds.), Creating social trust in post socialist transition: 193-212. New York: Palgrave Macmillan.

Fei, H. T. 1992. From the soil - The foundation of Chinese society. Berkeley, CA: University of California Press.

Fukuyama, F. 1995. Trust: The social virtues and the creation of prosperity. New York: Free Press.

Granovetter, M. 1973. The strength of weak tic. American Journal of Sociology, 78(6): 13601380.

Granovetter, M. 1974. Getting a job: A study of contracts and careers. Chicago, IL: University of Chicago Press.

Granovetter, M. 1985. Economic action and social structure: The problem of embeddedness. American Journal of Sociology, 91(3): 481-510.

Granovetter, M. 1992. The sociological and economic approaches to labor market analysis: A social structure vicw. In N. Nohria and R. G. Eccles (Eds.), The sociology of economic life: $25-57$. Boston: Harvard Business School Press.

Granovetter, M. 1995. The economic sociology of firms and entrepreneurs. In A. Portes (Ed.), The economic sociology of immigration - Essays on networks, ethnicity, and entrepreneurship: 128-165. New York: Russell Sage Foundation.

Granovetter, M. 2002. A theoretical agenda for economic sociology. In R. C. Mauro, F. Guillen, P. England \& M. Meyer (Eds.), The nere economic sociology: Development in an emerging field: $35-59$. New York: Russell Sage Foundation.

Granovetter, M. (forthcoming). Trust. The third chapter in Society and economy. Draft paper.

Hansen, M. T. 2002. Knowledge networks: Explaining effective knowledge sharing in multiunit companies. Organization Science, 13(3): 232-248.

Hardin, R. 200l. Conceptions and explanations of trust. In K. S. Cook (Ed.), Trust in society: 3-39. New York: Russel Sage Foundation.

Heider, F. 1958. The psychology of interpersonal relations. New York: Wilcy.

Hwang, K. K. 1987. Face and favor: The Chinese power game. American Joumal of Sociology, 92(4): 944-974.

Hwang, K. K. 1988. The Chinese power game. Taipci: Chi-Liu Press. 
Hwang, K. K. 2009. Confucian relationalism: Cultural reflection and theoretical construction. Beijing: Beijing U. Press.

Krackhardt, D. 1992. The strength of strong ties: The importance of philos in organizations. In $N$. Nohria \& R. G. Eccles (Eds.), Networks and organization: 25-56. Boston, MA: Harvard Business School Press.

Krackhardt, D., \& Hanson, J. 1993. Informal networks: The company behind the chart. Harvard Business Review, 71: 104-111.

Luo, J. D. 2005. Particularistic trust and general trust: A network analysis in Chinese organizations. Management and Organizational Review, 1(3): 437-458.

Mishra, A. K. 1996. Organizational responses to crises: The centrality of trust in organizations. In R. M. Kramer \& T. R. Tyler (Eds.), Trust in organizations: 261-287. London: Sage Publications, Inc.

Sluss, D., \& Ashforth, B. 2008. How relational and organizational identification converge: Processes and conditions. Organization Science, 19: 807-823.

Suarez, F. F. 2005. Network effects revisited: The role of strong ties in technology selection. Academy of Management Joumal, 48(4): 710-720.

Tsai, W. 2002. Social structure of 'cooperation' within a multiunit organization: Coordination, competition, and intra-organizational knowledge sharing. Organization Science, 13(2): 179-190.

Tsui, A. S., \& Farh, J. L. 1997. Where guanxi matters - relational demography, guanxi and technology. Work and Occupations, 24: 57-79.

Uzzi, B. 1997. Social structure and competition in inter-firm networks: The paradox of embeddedness. Administrative Science Quarterly, 42(1): 35-67.

Wang, S. K., \& Liu, X. 2003. The foundation of trust: An explanation of rationality. In Y. F. Zhang \& S. C. Peng (Eds.), Trust in Chinese society: 209-249. Beijing: Chinese City Press.

Williamson, O. 1996. The mechanisms of governance. New York: Oxford University Press.

Yamagishi, T., \& Yamagishi, M. 1994. Trust and commitment in the United States and Japan. Motivation and Emotion, 18(2): 129-166.

Yamagishi, T., Cook, K. S., \& Motoki, W. 1998. Uncertainty, trust, and commitment formation in the United States and Japan. American Journal of Sociology, 104(1): 165-195.

Yang, G. S. 1993. Chinese social orientation. In G. S. Yang \& A. B. Yu (Eds.), Chinese Psychology and Behavior: 87-142. Taipei: Laureate Press.

Yang, Y. Y. 1995. Analyzing guanxi and its categorics: Discussing with Hwang, Kuan Kuo. Sociological Studies, 5: 18-23.

Yang, Y. Y. 2001 . Inner circle members. In C. F. Yang (Ed.), Chinese social relations, emotion and trust: 131-157. Taipei: Laureate Press.

Zhai, X. W. 2001. The logics of Chinese actions. Beijing: Social Science Documentation Publication.

Zhai, X. W. 2005. Favors, face, and the reproduction of pozer. Beijing: Beijing University Press.

Zucker, L. G. 1986. Production of trust: Institutional sources of economic structure. Research in Organizational Behavior, 8: 53-111.

Jar Der Luo (jdluo@mail.tsinghua.edu.cn) is a Professor of Sociology at Tsinghua University in Beijing, and Chairman of the Chinese Network for Social Network Studies. He earned his Ph.D. in Sociology from the State University of New York at Stony Brook. His research interests include social network studies, including social capital, trust, and social network structure and Chinese indigenous management research, such as guanxi, small circle, and favour exchange.

Manuscript received: March 11, 2008

Final version accepted: April 18, 2011

Accepted by:

Joseph Galaskiewicz

(C) 2011 The Intcrnational Association for Chinese Management Research 